\title{
Stem Cell Derived Osteoprogenitors and their Role in Bone Repair Using Morphogenic Activators
}

George W. Brownridge III, Sylvanna Islas, Angelina Miller, Warren Hoeffler, Ph.D. Department of Natural Sciences and Mathematics, Dominican University of California, 50 Acacia Ave

\section{Abstract}

Bone constantly cycles through a dynamic process of breakdown and remodeling. Osteoblasts are the specialized mesenchymal stem cells that have a major role in bone formation and the remodeling process whereas their counterpart osteoclasts, handle bone resorption. Embryonic stem cells can be partially differentiated into Progenitor cells, and we worked with \#18, a candidate for being an osteoprogenitor that has the potential to respond to morphogenic activators. In the case of bone remodeling, TGF- $\beta 2$, BMP-2 and an abundance of CA++ have been shown to be potential activators of differentiation into osteoblasts. Eight different trials were conducted with the cells using different combinations of the three morphogenic activators. After inducing the cells with the activators, we performed Immunohistochemistry (IHC) to analyze the expression of osteocalcin, which is the enzyme that binds calcium to mineralize bone. The cells with varying activator combinations showed different physiology with a variance in the cell shape, structure, and spacing. The greatest results were from the combination of TGF- $\beta 2$ and BMP-2, which is consistent with \#18 operating as an osteoprogenitor. A 3D construct model of $\# 18$ seemed to have a similar structure to that of an osteon possibly indicating the formation of bone. We took slices of the model and performed an IHC staining for Osteocalcin, Prolyl Hydroxylase (5B5), and Collagen I. We saw a strong positive signal for Col I and 5B5, and a sligh positive signal for Osteocalcin. This information confirmed that $\# 18$ is an osteoprogenitor and is able to assemble bone.

\section{Introduction}

Human embryonic stem cells (hESC) are primordial, unspecialized cells that can differentiate into any other cell type. BioTime's business is to direct these hESC into progenitor cell lines with the potential to become differentiated into a variety of different cell types. One of Biotime's cell lines, progenitor \# 18, is a Mesenchymal stem cell (MSC line. Specialized MSC's can be potentially differentiated into muscle, tendons, ligaments, fat, and bone. MSC's are sensitive to the timing of tendons, ligaments, fat, and bone. MSC's are sensitive to the tim growth factor presentation and differentiation can be specializ toward osteoprogenitors responsible for bone formation and remodeling. We encompassed our research around the question of whether Progenitor \#18 cells have the potential to be differenth primary bone cells caller mesenchymal cells through the production of osteocalcin, which is responsible for the calcification of bone. This research could advance efforts in the field of bone repair.

\section{Materials and Methods}

- The cullure was grown in DMEM $10 \%$ FBS medium and treated to a $5 \mathrm{ml}$ PBS
- After centrifugation cell line was tived ens exposed to a combination of three morphogenic activators: BMP-2 (10 uL), TGF- $\beta 2$ (10 uL), and Ca - After 4 days of incubation images were taken for morphology and culture was returned to $37^{\circ} \mathrm{C}$ Cell Culture Immunohistochemistry (IHC)

-7 days after adding morphogenic activators, IHC was conducted.
- Cell were separated, marked by pap-pen and fixed to slide using Acetone methanol solution for 10 minutes at room temperature.
- Cells were stained for 50 minutes with a 1:200 dilution of primary antibodies, Osteocalcin and

- A second antibody was used at a 1:200 dilution of goat antimouse lgG 594 Red. - Cell culture was examined by conventional fluorescent microscope (Axiovert $40 \mathrm{CFL}$ ) with images 3D Construct Immunohistochemistry (IHC)

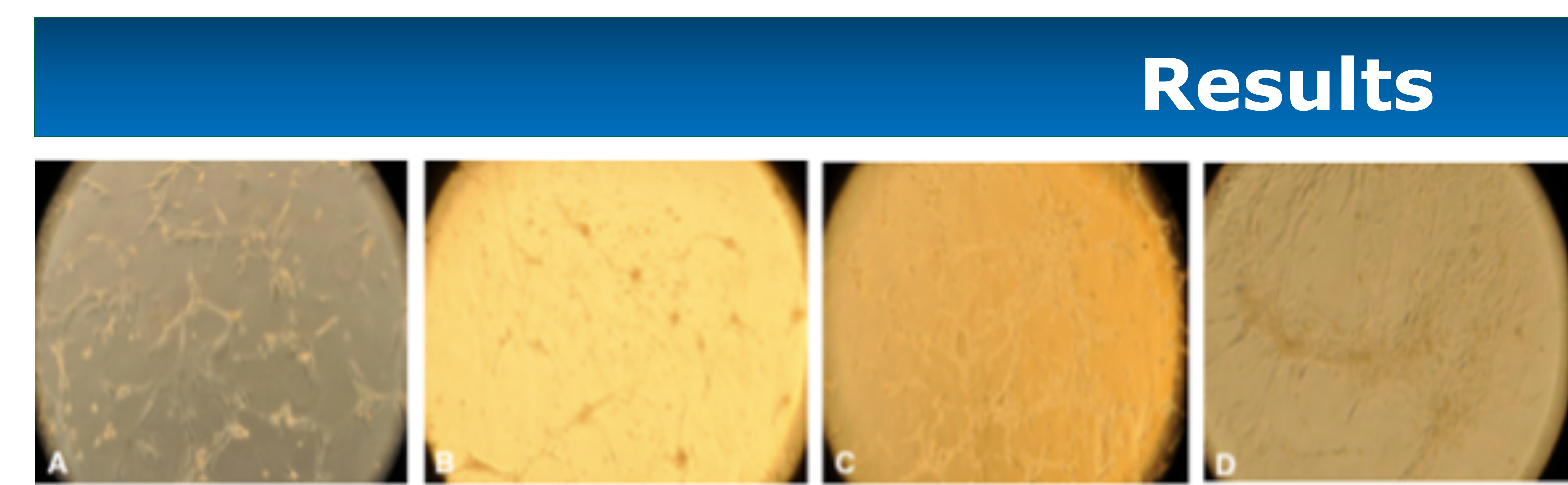

Figure 1: Changing morphology in response to morphogenic activators in \#18 (40x) P60 plate of line \#18 in the presence of morphological activators resulted in clear morphological changes. (A) The control line shows the normal morphology of line \#18. (B) Cells induced with BMP-2 began to spread out and become confuent. (C) Cells induced with TGF- $\beta 2$ began to cluster more after induction. (D) The cells treated with a

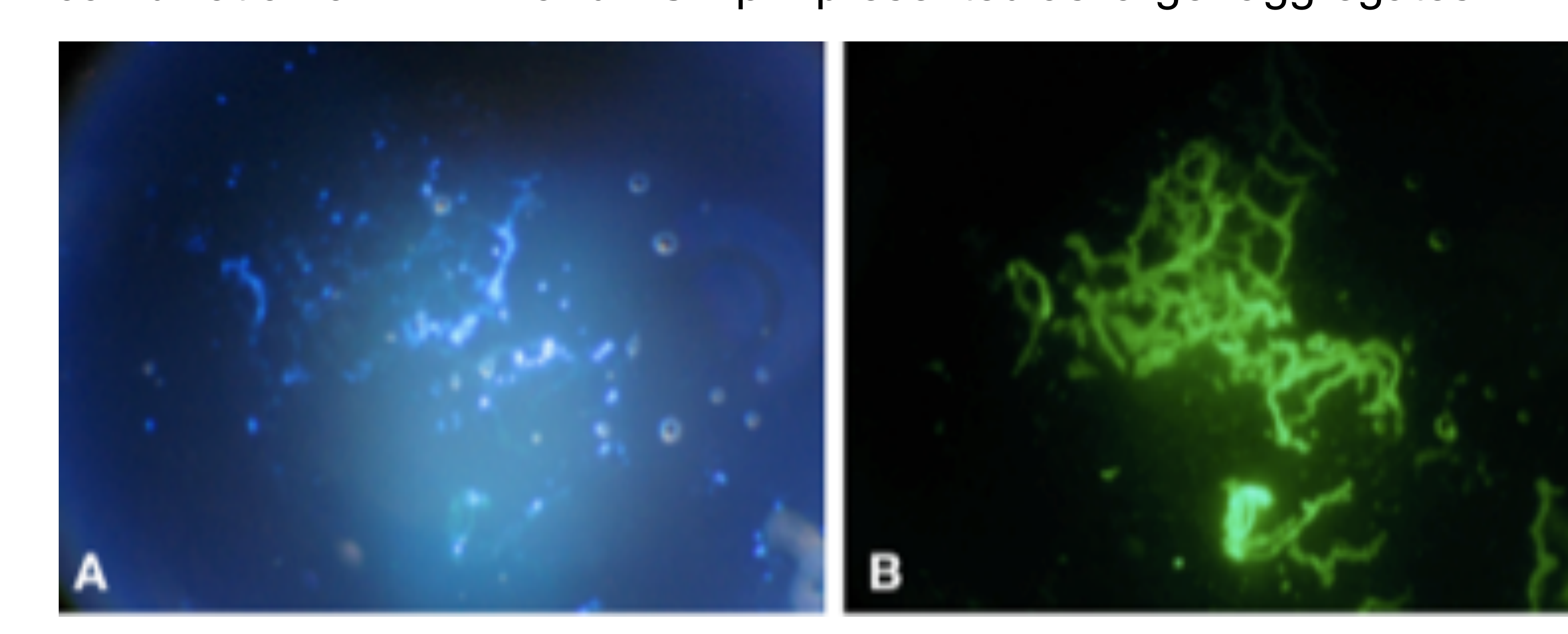

Figure 2: Collagen Expressed in 3D Model (40X) ffer taking slices of the $3 \mathrm{D}$ model, immunohistochemistry was performed to characterize the expression of Collagen I. (A) The DAP stain presents expression of Collagen I (B) Collagen I does not completely overlap the nuclei signaling that collagen is made in the vicinity of the cells.

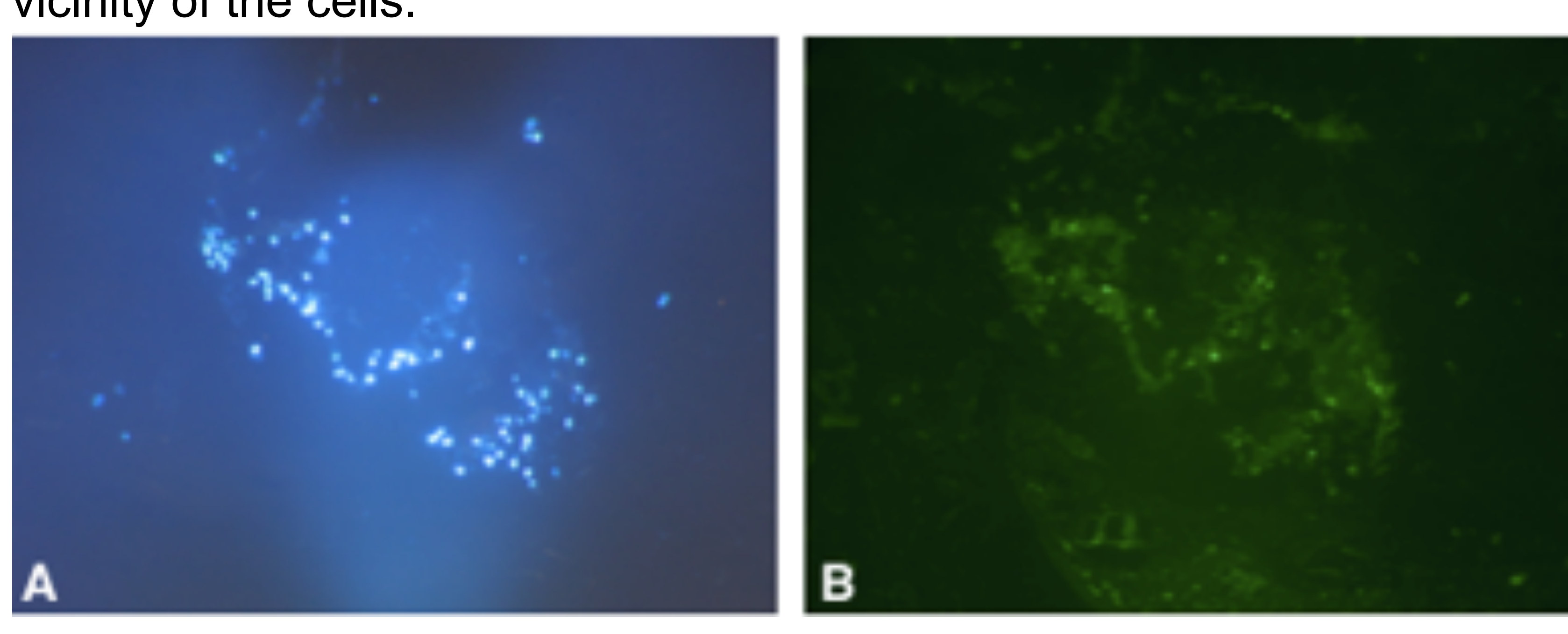

Figure 3: Osteocalcin Expressed in 3D Model (40X) After taking slices of the $3 \mathrm{D}$ model, immunohistochemistry was performed to characterize the expression of Osteocalcin (A) The DAPI stain expresses a positive expression for Osteocalcin. (B) IHC shows Osteocalcin does not completely overlap with the nuclei and is secreting osteoid beyond the boundaries of the cell, forming bone.

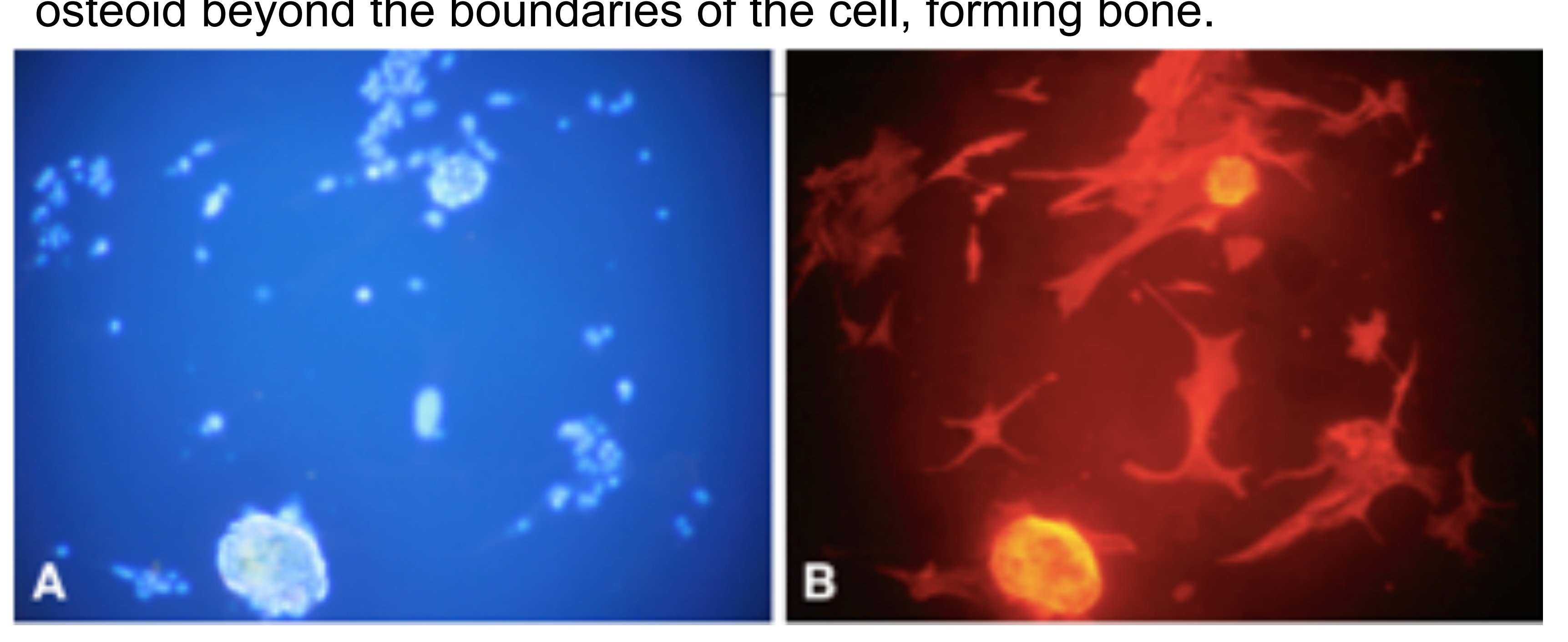

Figure 4: Progentior cells induced with BMP-2 and TGFB-2 express Osteocalcin

(A) Blue dots show DAPI staining of nuclei therefore the position of living cells. (B) Red staining shows that IHC staining was positive for Osteocalcin

\section{Acknowledgements}

The authors wish to thank our professor, Dr. Hoeffler for his dedication to and support for our
research. We would also like to thank Dominican University of California, Xgene Corporation and BioTime for their generous contributions to this research project.
Figure 5: Embryonic Stem Cell (ESC) Differentiation to Bone Cells

Our collaborator "BioTime inc" took ESCs and derived Mesenchymal Stem Cells (MSC) \#18. We tested to see if these cells could be manipulated into becoming bone cells (osteoblasts) by adding BMP-2 and TGFB-2. We saw Collagen 1 and Osteocalcin in $\mathrm{IHC}$ which indicates positive bone cell formation.

\section{Conclusions}

- Human Embryonic Stem Cells can be partially differentiated into progenitor cell lines. We chose \#18 as a candidate for the formation of osteoblasts.

- We tested factors that trigger Osteoblast formation and saw that the combination of TGFB-2, BMP-2 was successful.

- We conclude that cell line \#18 is an osteoprogenitor with the potential to assemble bone.

\section{References}

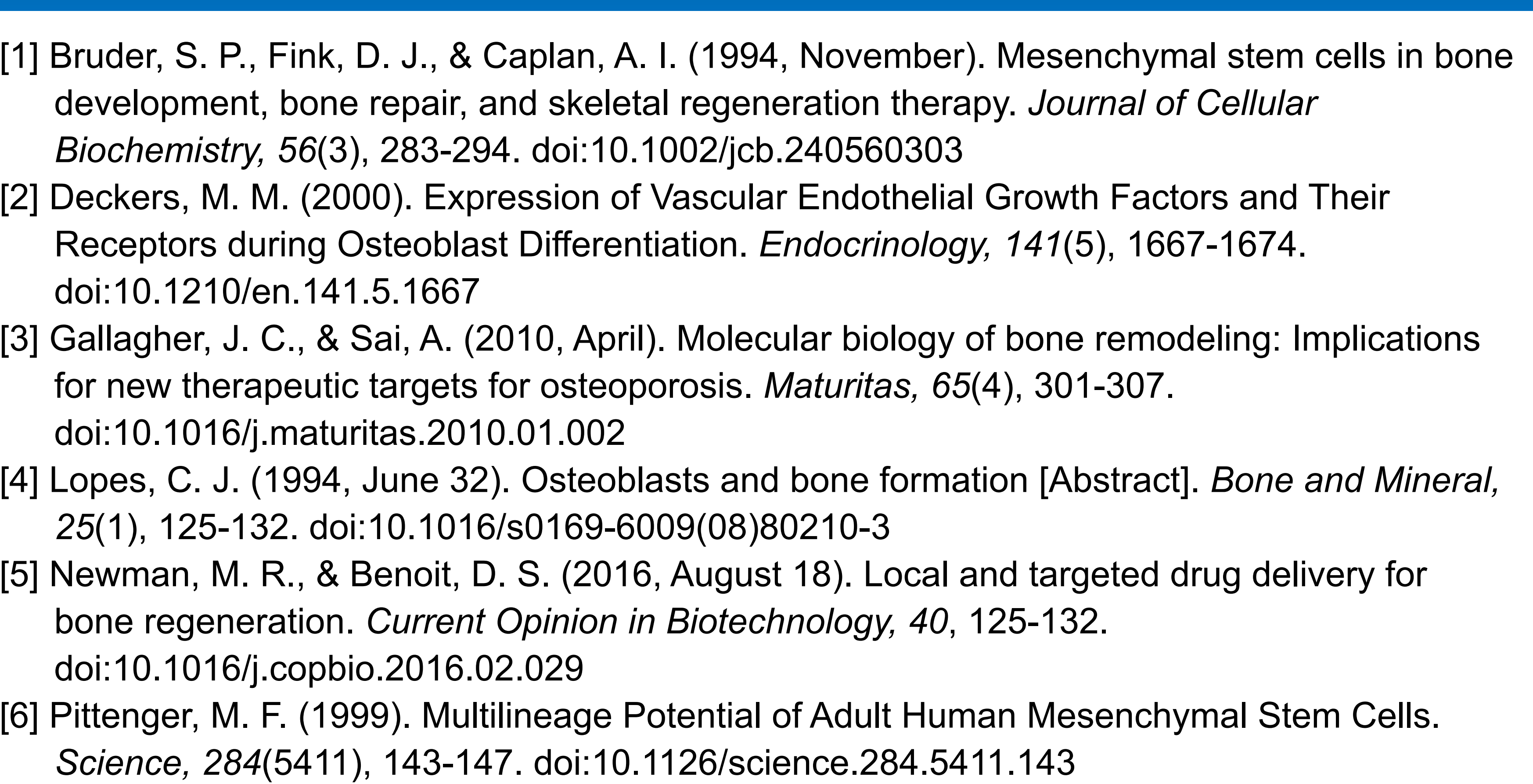

